City University of New York (CUNY) CUNY Academic Works

2000

\title{
Attentional Modulation of Language Performance
}

\author{
Lisa Tabor Connor \\ Boston University \\ Martin L. Albert \\ Boston University \\ Nancy Helm-Estabrooks \\ Boston University \\ Loraine Obler \\ CUNY Graduate Center
}

\section{How does access to this work benefit you? Let us know!}

More information about this work at: https://academicworks.cuny.edu/gc_pubs/54

Discover additional works at: https://academicworks.cuny.edu

This work is made publicly available by the City University of New York (CUNY).

Contact: AcademicWorks@cuny.edu 


\title{
Attentional Modulation of Language Performance
}

\author{
Lisa Tabor Connor and Martin L. Albert
}

Harold Goodglass Aphasia Research Center, Department of Neurology, Boston University School of Medicine and Research Service of the Department of Veterans Affairs Medical

Center, Boston; and Language in the Aging Brain Laboratory, Boston University

School of Medicine

\section{Nancy Helm-Estabrooks}

Harold Goodglass Aphasia Research Center, Department of Neurology, Boston University School of Medicine and Research Service of the Department of Veterans Affairs Medical

Center, Boston; and National Center for Neurogenic Communication Disorders,

University of Arizona

and

\section{Loraine K. Obler}

Harold Goodglass Aphasia Research Center, Department of Neurology, Boston University School of Medicine and Research Service of the Department of Veterans Affairs Medical Center, Boston; Language in the Aging Brain Laboratory, Boston University School of Medicine; and CUNY Graduate Center, Program in Speech and Hearing Sciences

During the last quarter of this century, neuroscientists have gained indepth knowledge of the operations of individual cognitive abilities-language, memory, and attention. It is now time for neurolinguists to integrate these cognitive functions to produce a cognitive neuroscience of language as a whole, addressing the dynamic interplay among cognitive abilities. Toward that goal, inroads have been made recently in investigating the interaction between memory and attention in working memory for language (e.g., Carpenter, Miyake, \& Just, 1994; D’Esposito, Detre, Alsop, Shin, Atlas, \& Grossman, 1995; Waters \& Caplan, 1996a, 1996b). There has been increasing momentum in exploring the extent to which other aspects of cognition

We gratefully acknowledge the support of the James S. McDonnell Foundation and the NIH, DC 00081.

Address correspondence and reprint requests to Lisa Tabor Connor, Ph.D., VA Medical Center (12A), 150 S. Huntington Avenue, Boston, MA 02130. E-mail: lconnor@bu.edu. 
may influence or account for the performance deficits seen in aphasia. Our research group has been focusing on the interaction of attentional processes and auditory comprehension in aphasic individuals. We use the example of attentional modulation of comprehension to argue for the importance of interplay between language and attention.

Aphasiologists, to a great extent, have been invested in the concept of aphasia as a purely linguistic deficit in order to build and test models of language processing and its instantiation in the brain. Moreover, the characterization of aphasia as a linguistic deficit has profoundly influenced aphasia therapy methods. The field of clinical aphasiology has developed under the central assumption that dysfunction of language is the principal cognitive deficit in aphasia and should be the primary target of rehabilitation. Only recently (Helm-Estabrooks, 1998; Holland, 1994) has this central assumption been called into question. Although cognitive approaches to rehabilitation have been proposed (e.g., Seron \& Deloche, 1989; Schwartz, Saffran, Fink, Myers, et al., 1994), they have largely emphasized detailed cognitive descriptions of the language deficit, rather than the interaction of the various cognitive abilities.

There are several studies in the literature that highlight the importance of attentional processing in the language deficits exhibited in aphasia. Three lines of evidence converge on the crucial role of attentional deficiencies in aphasia that produce auditory comprehension deficits. First, individuals with aphasia exhibit substantial variability in performance on tasks of auditory comprehension (McNeil, 1983), a result borne out in work in our laboratory. Our detailed examination of patients' performance on multiple pretreatment assessments has revealed substantial retest inconsistency at the level of individual items, despite stability in overall auditory comprehension scores. We believe that this variability in performance implicates fluctuating access to intact language representations due to attentional fluctuation. A second line of evidence comes from studies investigating the role of interfering auditory information in both linguistic and nonlinguistic judgments in aphasic persons. In these studies (Erickson, Goldinger, \& LaPointe, 1996; LaPointe \& Erickson, 1991; Murray, Holland, \& Beeson, 1997a, 1997b), linguistic and nonlinguistic judgments were compromised when competing auditory stimuli were present, even though it was not necessary for them to be attended to. A third line of evidence is that extra-linguistic stimulation can enhance the performance of aphasic individuals on tasks of auditory comprehension. Slowing the rate of input (Albert \& Bear, 1974; Blumstein, Katz, Goodglass, Shrier, \& Dworetsky, 1985; Campbell \& McNeil, 1985), providing emphatic stress (Kimelman \& McNeil, 1987; Slansky \& McNeil, 1997), or providing an alerting signal (Loverso \& Prescott, 1981) all serve to improve auditory comprehension.

If we acknowledge that disruptions of the attentional system affect auditory comprehension, what next? We believe that the pertinent questions to 
be answered in the next century are: To what degree are attentional abilities compromised in persons with aphasia? What are the characteristics of the attentional deficits? Are they general or language-specific? Can these attentional dysfunctions be rehabilitated? How? What is the extent of the remaining language deficit in auditory comprehension? We believe that seeking the answers to these questions will have a significant impact on the development of the cognitive neuroscience of language and the opportunity to maximize functional communication in individuals with aphasia. The difficulties that lie ahead are in developing an adequate description of attentional deficits of each person with aphasia, in determining the degree to which distributed systems of attention are affected by brain lesions, and in capturing the dynamics of attention/language interaction both in momentto-moment language processing and throughout the time-course of recovery from aphasia.

\section{REFERENCES}

Albert, M. L., \& Bear, D. 1974. Time to understand: A case study of word deafness with reference to the role of time in auditory comprehension. Brain, 97, 373-384.

Blumstein, S. E., Katz, B., Goodglass, H., Shrier, R., \& Dworetsky, B. 1985. The effects of slowed speech on auditory comprehension in aphasia. Brain and Language, 24, 246265.

Campbell, T. F., \& McNeil, M. R. 1985. Effects of presentation rate and divided attention on auditory comprehension in children with an acquired language disorder. Journal of Speech and Hearing Research, 28, 513-520.

Carpenter, P. A., Miyake, A., \& Just, M. A. 1994. Working memory constraints in comprehension: Evidence from individual differences, aphasia, and aging. In M. A. Gernsbacher (Ed.), Handbook of psycholinguistics (pp. 1075-1122). San Diego: Academic Press.

D’Esposito, M., Detre, J. A., Alsop, D. C., Shin, R. K., Atlas, S., \& Grossman, M. 1995. The neural basis of the central executive system of working memory. Nature, 378, 279-281.

Erickson, R. J., Goldinger, S. D., \& LaPointe, L. L. 1996. Auditory vigilance in aphasic individuals: Detecting nonlinguistic stimuli with full or divided attention. Brain and Cognition, 30, 244-253.

Helm-Estabrooks, N. 1998. A “cognitive" approach to treatment of an aphasic patient. In N. Helm-Estabrooks and A. L. Holland (Eds.), Approaches to the treatment of aphasia (pp. 69-89). San Diego: Singular Publishing Group, Inc.

Holland, A. L. 1994. Cognitive neuropsychological theory and treatment for aphasia: Exploring the strengths and limitations. Clinical Aphasiology, 22, 275-282.

Kimelman, M. D. Z., \& McNeil, M. R. 1987. An investigation of emphatic stress comprehension in adult aphasia: A replication. Journal of Speech and Hearing Research, 30, 295300.

LaPointe, L. L., \& Erickson, R. J. 1991. Auditory vigilance during divided task attention in aphasic individuals. Aphasiology, 5, 511-520.

Loverso, F. L., \& Prescott, T. E. 1981. The effect of alerting signals on left brain damaged (aphasic) and normal subjects' accuracy and response time to visual stimuli. Clinical Aphasiology, 11, 55-67. 
McNeil, M. R. 1983. Aphasia: Neurological considerations. Topics in Language Disorders, 1, 1-19.

Murray, L. L., Holland, A. L., \& Beeson, P. M. 1997a. Auditory processing in individuals with mild aphasia: A study of resource allocation. Journal of Speech, Language, and Hearing Research, 40, 792-808.

Murray, L. L., Holland, A. L., \& Beeson, P. M. 1997b. Grammaticality judgements of mildly aphasic individuals under dual-task conditions. Aphasiology, 11, 993-1016.

Seron, X., \& Deloche, G. (Eds.). 1989. Cognitive approaches in neuropsychological rehabilitation. Hillsdale, NJ: Erlbaum.

Schwartz, M. F., Saffran, E. M., Fink, R. B., Myers, J. L., et al. 1994. Mapping therapy: A treatment programme for agrammatism. Aphasiology, 8, 19-54.

Slansky, B. L., \& McNeil, M. R. 1997. Resource allocation in auditory processing of emphatically stressed stimuli in aphasia. Aphasiology, 11, 461-472.

Waters, G. S., \& Caplan, D. 1996. The capacity theory of sentence comprehension: Critique of Just and Carpenter (1992). Psychological Review, 103, 761-772.

Waters, G. S., \& Caplan, D. 1996. Processing resource capacity and the comprehension of garden path sentences. Memory and Cognition, 24, 342-355. 